\title{
Editorial
}

\section{What Standards Apply to Resuscitation at the Borderline of Gestational Age?}

John J. Paris, PhD

Journal of Perinatology (2005) 25, 683-684. doi:10.1038/sj.jp.7211401

Mercurio's article on "Resuscitation at the Borderline of Gestational Age"1 raises anew the issue the EPICure study ${ }^{2}$ describes as among the most difficult and trying clinical problems confronting parents and pediatricians alike: the care of infants born at the threshold of viability. More specifically, it probes the physician's role in determining whether or not to initiate resuscitation on the 22 to 23 weeks gestational age infant. As Mercurio notes, data from a recent poll of neonatologists in Connecticut and Rhode Island indicate that even if requested, 11\% of neonatologists surveyed would refuse to resuscitate at 23 completed weeks, $67 \%$ would decline at 22 weeks, and $91 \%$ would refuse at 21 weeks. The issue is not whether a physician would reject a parental request to resuscitate, but what standard the physician should use to determine the cutoff point.

In his response to that question, Mercurio notes that estimated gestational age is not accurate enough to serve as the standard. Estimates based on last menstrual period or first trimester uterine size can be off by as much as 2 weeks. As Magruples and Cople note, even the second trimester ultrasound is accurate only to within 10 to 14 days. ${ }^{3}$ Further, if we simply accept the prevailing success rate as the lowest most reach of possibility, we have a self-fulfilling prophecy. Under those conditions improvement in survival rates would never occur.

How then do physicians make a principled decision on when to attempt resuscitation? Societal standards on that question have shifted significantly over the past several decades. ${ }^{4}$ In their landmark 1973 essay in the New England Journal of Medicine on "Moral Dilemmas in the Newborn Nursery", Duff and Campbell proposed that the decision to withhold or withdraw treatment belonged to those who are responsibile for the consequences of the treatment — the families. ${ }^{5}$ Their article, unfortunately, provided no guidelines, no standards, no norms on which to base such decisions. The treatment choice could equally be made on concern for siblings or "family convenience" as on the interests of the infant.

A radically different position — "always treat" — was found in the now well-known Stinson case in which a "marginally

Department of Theology (J.J.P.), Boston College, Chestnut Hill, MA, USA.

Address correspondence and reprint requests to John J. Paris S.J., Department of Theology, Boston College, Chestnut Hill, MA 02467, USA. viable" $800 \mathrm{~g}$ infant born in 1983 was aggressively treated even though at the time there was only a 5\% survival rate for such infants. In that case, despite the parents pleas to stop the "heroic" attempts to sustain their child's life, the physicians would not withdraw treatment. ${ }^{6}$ Their response to the parents' requests was, "A baby must be saved at all costs: anything less is illegal and immoral." Brain death was the only criterion they would recognize as a legitimate basis for ceasing medical interventions.

The attitude of the physicians in the Stinson case briefly became official government policy in the United States in the early 1980s with the now infamous "Baby Doe" regulations. ${ }^{7}$ Those regulations were struck down by a federal court on procedural grounds. In the ensuing debate it became clear that the onerous burden of aggressive treatment for all infants, including those who were clearly dying, was abusive and unwarranted.

Out of that debate a consensus emerged that for the never competent patient — which includes infants — the standard that should guide treatment decision is the "best interest" of the patient. ${ }^{8}$ That standard, unlike the "autonomy" model that prevails for competent adults, does not rest on the value of selfdetermination. Rather, it focuses on the protection of the patient's welfare. That protection is particularly important with regard to infants because they are now seen not merely as the property of parents, but as patients in their own right. The implication is that, although parents may continue to be involved in decision-making for their children, they do not have the exclusive right to refuse — or to demand — medical treatment for the child. ${ }^{9}$

Society's commitment to protect the newborn from the neglect of undertreatment or the abuse of excessive treatment is an overriding consideration. It is the neonatologist who has the responsibility of protecting the infant's interests when a parent makes a decision believed to be antithetical to the welfare of a newborn. There is little hesitation by physicians in intervening with child protective services to protect an infant against neglect or abuse by parents who fail to provide necessary and appropriate treatment. ${ }^{10} \mathrm{~A}$ more difficult decision is challenging a parent's demand for continued life-prolonging treatment believed by the physician to be ineffective and unwarranted.

Such an action occurred in the recent case of Hudson $v$. Texas Children's Hospital. ${ }^{11}$ The case involved a full-term baby born with thanatrophoric dysplasia, a lethal genetic condition characterized by a narrow small chest, small ribs, and underdeveloped lungs. The mother had not had any prenatal care. The physicians were unaware of the fetus' medical status and so at delivery resuscitated 
the newborn. When an evaluation of the infant, named Sun Hudson, revealed the lethal abnormality, the doctors recommended withdrawal of treatment. The mother refused.

The mother, who spent 3 days in a psychiatric facility after the child's birth, told the doctors that her child "just needs to finish growing." Further, she informed the doctors that "the Sun that shines in the sky, not a man, fathered her child and would decide its fate."12 According to her, "As long as the Sun is in the sky he will live." The neonatologists judged that Sun Hudson was "slowly suffocating because his lungs lack the capacity to support his body." 13 Given that reality, the doctors and ethicists at Texas Children's believed it was inhumane and unethical to continue mechanical ventilation of the infant. ${ }^{14}$

A 1999 Texas statute allowed doctors and hospitals to withdraw life-prolonging interventions even over family objections if the action were approved by an ethics committee and no other facility could be found (within 10 days), which was willing to treat the patient as the family demanded. ${ }^{15}$ Even though some 40 hospitals had declined to accept the child on transfer, the physicians at Texas Children's were reluctant to withdraw treatment because of the mother's questionable mental status. The hospital sought a court resolution of the issue. A Harris County Probate judge heard the case and ruled that under Texas law since no other facility could be found that was willing to treat the child as the mother wished, Texas Children's Hospital had no obligation to continue medical treatment. That ruling was appealed.

The 1st Texas Court of Appeals in Houston did not address the underlying issue. Rather, it sent the case back to the probate judge on a procedural question. That issue was quickly resolved and the probate judge again ruled that the hospital was authorized under the Texas statute to withdraw treatment. ${ }^{16}$ No further appeal was taken. On March 15, 2005 - nearly 6 months after Sun Hudson's birth - the respirator was turned off. The child died moments later.

The ruling in the Hudson case when coupled with the Texas Supreme Court's recent opinion in Miller v. $H_{C A}{ }^{17}$ that a physician could resuscitate a child over parental objection in a situation where there is a risk of death before a court could review the legitimacy of the parental refusal, gives enormous discretion to physicians in the determination of whether or not to resuscitate a newborn. In making that decision the physician should note well Mercurio's observation that when the benefit/burden assessment is ambiguous - as it surely is in the 22 to 23 weeks gestation age period $^{18}$ - it is appropriate for the physician to defer to the parents.

In making the benefit/burden assessment, consideration must be given not only to survival rates, but to the long-term neurodevelopmental sequelae for extremely low-birth-weight infants. Hack et al's ${ }^{19}$ recent report of "extremely high rates" of long-term health and educational problems for such infants highlights the fact that the benefit/burden calculus in these cases is both more complex and more subjective than an evaluation of survival data alone. Such judgments are intensely personal and highly individualistic. They are necessarily subjective not scientific in nature. As such these assessments belong not to a physician, but to the parent.

It is only on those rare occasions when it is obviously not in the infant's best interest to undergo resuscitation such as an infant born with anencephaly, Potter's Syndrome or thanatrophoric dysplasia or a neonate delivered at $<22$ weeks gestational age that a physician should refuse a parental request to initiate resuscitation. In all other circumstances, if asked, "resuscitate and then evaluate" should be the norm.

\section{References}

1. Mercurio MR. Physicians' refusal to resuscitate at borderline gestational age. J Perinatol 2005.

2. Costilo K, Hennessey E, Gibson AT, et al. The EPICure study: outcomes to discharge from hospital for infants born at the threshold of viability. Pediatrics 2004;106:659-77.

3. Magruples V, Copel J. Obstetric Management of the High Risk Patient. In: Burrow GN, Duffy TP, Copel J, editors. Medical Complications During Pregnancy. 6th ed. Philadelphia: Elsevier Saunders; 2004. p. 1-14.

4. Paris JJ, Ferrante J, Reardon F. From the Johns Hopkins Baby to Baby Miller: what have we learned from four decades of reflection on neonatal cases? J Clin Ethics 2001;12:207-14.

5. Duff RS, Campbell AGM. Moral and ethical dilemmas in the special care nursery. N Engl J Med 1973;289:890-4.

6. Stinson R, Stinson P. The Long Dying of Baby Andrew. Boston: Little Brown; 1983.

7. Pless JE. The story of Baby Doe. N Engl J Med 1983;309:664-8.

8. Caplan A, Cohen CB. Ed. Imperiled newborns. Hast Cent Rept 1987;17(6):1-52

9. Paris JJ, Schreiber MD. Parental discretion in refusal of treatment for newborns: a real but limited right. Clinics in Perinatology 1996;23:573-81.

10. Paris JJ, Bell AJ. Guarantee my child will be normal or stop all treatment. J Perinatol 1993;13:469-72.

11. Hudson v. Texas Children's Hospital. Court of Appeals of Texas, Houston (1st Dist.). No. 01-05-00143-CV. March 1, 2005.

12. Nichols B. Hospital ends life support of baby: 1st case of its kind is against mom's wish, in accordance with law. The Dallas Morning News 2005;1.

13. Hopper L. Ruling keeps baby on life support/mom given time to find alternatives after hospital says case is hopeless. Houston Chronicle 2005;1.

14. Hopper L. Dying infant to remain on life support. Houston Chronicle 2005;1.

15. Texas Health and Safety Code \$166.046(a) (Vernon Supp 2002).

16. Hopper L. Judges rules infant can be pulled from life support. Houston Chronicle 2005;1

17. Paris JJ, Schreiber MD, Reardon F. The "emergent circumstances" exception to the need for consent: the Texas Supreme Court ruling in Miller v HCA. J Perinatol 2004;24:337-42.

18. Tyson JE, Saigal S. Outcomes for extremely low-birth-weight infants. JAMA 2005;294:371-3.

19. Hack M, Taylor HG, Drotar D, et al. Chronic conditions, functional limitations, and special health care needs of school-age children born with extremely low-birth-weight in the 1990s. JAMA 2005;294:318-25. 